ARTIGO

do https://doi.org/10.22481/praxisedu.v15i34.5468

\title{
UTILIZAÇÃO DE ARTEFATOS GOOGLE FOR EDUCATION EM ESTRATÉGIAS PENSADAS PARA METODOLOGIAS ATIVAS
}

\author{
USE OF GOOGLE FOR EDUCATION ARTEPHATES IN STRATEGIES THOUGHT FOR \\ ACTIVE METHODOLOGIES
}
UTILIZACIÓN DE ARTEFACTOS GOOGLE FOR EDUCATION EN ESTRATEGIAS PENSADAS PARA METODOLOGÍAS ACTIVAS

\author{
Louise de Quadros da Silva \\ Universidade La Salle - Brasil \\ Hildegard Susana Jung \\ Universidade La Salle - Brasil \\ Paulo Fossatti \\ Universidade La Salle - Brasil
}

\begin{abstract}
Resumo: Este artigo possui como tema as estratégias de ensino e os artefatos da Google For Education utilizados na educação por metodologias ativas. O objetivo trata de suscitar o debate em busca da utilização de artefatos Google For Education em estratégias de ensino para uma metodologia ativa. Trata-se de pesquisa qualitativa, de cunho bibliográfico, com busca de materiais em livros, periódicos, anais de eventos, entre outros. Destacamos como principais resultados cinco estratégias possibilitadoras de metodologias ativas de ensino, que são: Aprendizagem baseada em problemas; Aprendizagem baseada em projetos; Aprendizagem pelos colegas; Aprendizagem baseada em equipes; e Sala de aula invertida. Concluímos que os artefatos Google For Education contêm diversas possibilidades para um ensino de qualidade que podem oferecer autonomia ao estudante além da possibilidade de uso nas diferentes estratégias mencionadas, a fim de uma educação por metodologias ativas.
\end{abstract}

Palavras-chave: Google For Education; Metodologias Ativas; Educação Superior.

\begin{abstract}
This article focuses on teaching strategies and Google For Education artifacts used in education through active methodologies. The goal is to spark the debate for the use of Google For Education artifacts in teaching strategies for an active methodology. It is a qualitative research, of a bibliographic nature, with search of materials in books, periodicals, annals of events, among others. We highlight as main results five strategies that enable active teaching methodologies, which are: Problem-based learning; Project-based learning; Peer learning; Team-based learning; and Inverted Classroom. We conclude that the Google For Education artifacts contain several possibilities for a quality teaching that can offer autonomy to the student besides the possibility of use in the different strategies mentioned, in order to have an education by active methodologies.
\end{abstract}

Key-words: Google For Education; Active Methodologies; College education. 
Resumen: Este artículo posee como tema las estrategias de enseñanza y los artefactos de Google For Education utilizados en la educación por metodologías activas. El objetivo trata de suscitar el debate buscando la utilización de artefactos Google For Education en estrategias de enseñanza para una metodología activa. Se trata de investigación cualitativa, de cuño bibliográfico, con búsqueda de materiales en libros, periódicos, memorias de eventos, entre otros. Destacamos como principales resultados cinco estrategias posibilitadoras de metodologías activas de enseñanza, que son: Aprendizaje basado en problemas; Aprendizaje basado en proyectos; Aprendizaje con los colegas; Aprendizaje basado en equipos; y Sala de clase invertida. Concluimos que los artefactos Google For Education contienen distintas posibilidades para una enseñanza de cualidad que pueden ofrecer autonomía al estudiante además de la posibilidad de uso en las diferentes estrategias mencionadas, con objetivo de una educación por metodologías activas.

Palabras-clave: Google For Education; Metodologías Activas; Educación Superior.

\section{Introdução}

O ensino tradicional, no qual o professor é elemento principal, já não funciona mais como antigamente (PAIVA, 2016). A nova geração de estudantes busca uma educação com métodos mais atrativos, que os mantenham interessados, e neste sentido surgiram as metodologias ativas de ensino. Estamos inseridos em uma realidade de diversidades que afetam a sociedade em geral e não seria diferente na área educacional. Para acompanhar a evolução tecnológica, os docentes precisam estar apropriados destes recursos, além de preparados para o uso de estratégias possibilitadoras de novas metodologias que vêm ganhando cada vez mais espaço na educação superior.

Após caracterizar metodologias ativas conforme Barbosa e Moura (2013), Paiva (2016), Gastardelli (2016), Farias, Martin e Cristo (2015), Bandeira, Silva e Vilela (2017), Santos, Oliveira e Alves (2016), Bergmann e Sams (2016), Nóbrega, Da Costa e Araújo (2016), Mendes et. al. (2017), entre outros, verificamos que surgem constantemente novas estratégias de ensino. Estas implicam na necessidade de adaptações por parte das instituições e profissionais da área, além de instrumentos que possibilitem o processo de ensinoaprendizagem de forma ativa.

As metodologias ativas de ensino buscam desenvolver estudantes autônomos, capazes de obter seu próprio conhecimento, envolvendo-se em sua educação. Estas, são tratadas segundo Valente, Almeida e Geraldini (2017, p. 463) como possuidoras de "[...] estratégias pedagógicas que colocam o foco do processo de ensino e aprendizagem no aprendiz”. 
Em meio a diversos artefatos ${ }^{1}$ utilizados nas estratégias de educação ativa, destacam-se os aplicativos Google For Education como viabilizadores das metodologias ativas. Isso porque esta plataforma comtempla aplicativos que possibilitam o ensino por diferentes formas. Sendo assim, este trabalho tem como objetivo suscitar o debate em busca da utilização de artefatos Google For Education em estratégias para uma metodologia ativa de ensino. Para tal, tivemos como orientadores metodológicos Gil (2002), e Kauark, Manhães e Medeiros (2010). Como referencial teórico para análise, contamos com artigos, dissertações, livros, entre outros disponibilizados na internet em plataformas como o Google Acadêmico ${ }^{2}$, Repositório Aberto ${ }^{3}$ e Biblioteca Digital Brasileira de Teses e Dissertações (BDTD) ${ }^{4}$.

Dentre essas estratégias consideradas potencializadoras do ensino por meio de metodologias ativas, alguns exemplos são projetos ou solução de problemas (BARBOSA; MOURA, 2013). Também verificamos a aprendizagem pelos colegas, a aprendizagem baseada em equipes, e a sala de aula invertida, as quais descrevemos na sequência. Após, apresentamos a metodologia utilizada para esta pesquisa, seguida das estratégias de ensino analisadas. Por fim, seguem as considerações finais e as referências que embasaram o estudo.

\section{Metodologia de pesquisa}

Conforme Kauark, Manhães e Medeiros (2010, p. 24), a pesquisa é a busca pela resposta de algo, nas palavras dos autores: "Pesquisar, portanto, é buscar ou procurar resposta para alguma coisa. Em se tratando de Ciência, a pesquisa é a busca de solução a um problema que alguém queira saber a resposta". Para esse estudo escolhemos trabalhar com a pesquisa qualitativa, de cunho bibliográfico, descrita por Gil (2002) como aquela que é elaborada a partir de materiais publicados como, por exemplo, artigos, livros, periódicos, entre outros. Tal pesquisa tem como fundamentador para a elaboração do objetivo principal, Gil (2002, p. 41) que o conceitua como “[...] o aprimoramento de ideias ou a descoberta de intuições”.

Após a escolha do tipo de pesquisa passamos a planejar as suas etapas, baseando-nos nas quatro grandes fases descritas por Kauark, Manhães e Medeiros (2010, p. 29-32): "Escolha do tema e elaboração do projeto da pesquisa; [...] Coleta de Material/Informações;

\footnotetext{
${ }^{1}$ A Google utiliza o termo ferramentas, mas escolhemos utilizar artefatos pois nos baseamos no entendimento de Rabardel (1999), ao descrevê-lo como objetos modificados através da interação do homem. Nas palavras do próprio autor: "Nous utilisons le concept d'artefact pour désigner de façon neutre toute chose tinalisée d'origine humaine. Les artefacts peuvent aussi bien étre matériels que symboliques" (RABARDEL, 1999, p. 245).

${ }^{2}$ Disponível em: https://scholar.google.com.br/

${ }^{3}$ Disponível em: https://repositorioaberto.uab.pt/

${ }^{4}$ Disponível em: http://bdtd.ibict.br/vufind/
} 
[...] Seleção e organização do material coletado; [...] Redação final e divulgação". Além disso, realizamos a organização minuciosa através das nove etapas de Gil (2002, p. 59-60) “[...] escolha do tema; levantamento bibliográfico preliminar; formulação do problema; elaboração do plano provisório de assunto; busca das fontes; leitura do material; fichamento; organização lógica do assunto; e redação do texto". Para a busca de materiais pertinentes, Gil (2002) descreve algumas fontes, a saber: livros de leitura corrente, obras de referência, teses e dissertações, além de anais de encontros científicos, periódicos indexados e resumos. Nesta pesquisa, para a obtenção de bibliografia, utilizamos principalmente, BDTD, Repositório Aberto e Google Acadêmico.

Após o entendimento metodológico conforme os autores acima, redigimos as quatro etapas descritas por Kauark, Manhães e Medeiros (2010) de maneira a englobar os nove passos de Gil (2002). Em um primeiro momento chamado por Kauark, Manhães e Medeiros (2010) como "Escolha do tema e elaboração do projeto da pesquisa" definimos o tema da pesquisa buscando atender a uma questão da atualidade e ainda pouco investigada. Como segundo passo, elaboramos o plano provisório de assunto e definimos o problema da investigação, além de estabelecer seus objetivos. Após, na segunda etapa descrita por Kauark, Manhães e Medeiros (2010) como “Coleta de Material/Informações” fizemos o levantamento bibliográfico preliminar a partir de resumos, utilizando palavras-chave e sinônimos para buscar materiais pertinentes em plataformas online e fontes confiáveis e relevantes ao assunto.

$\mathrm{Na}$ terceira etapa, assim como descrevem Kauark, Manhães e Medeiros (2010), passamos pela "Seleção e organização do material coletado", fazendo a leitura minuciosa dos materiais pertinentes encontrados; o fichamento dos conteúdos para facilitar a escrita; e a organização lógica do assunto. Finalizamos com a quarta etapa que, segundo Kauark, Manhães e Medeiros (2010) é a "Redação final e divulgação", na qual realizamos a organização dos achados para elaborar o artigo. Portanto, a partir dos autores deste tópico, distribuímos nossas etapas de pesquisa conforme o quadro 01

Quadro 01: Síntese metodológica

\begin{tabular}{|c|c|}
\hline Kauark, Manhães e Medeiros (2010) & Gil (2002) \\
\hline \multirow{3}{*}{$\begin{array}{l}\text { Escolha do tema e elaboração do } \\
\text { projeto da pesquisa }\end{array}$} & Escolha do tema; \\
\hline & Elaboração do plano provisório de assunto; \\
\hline & Formulação do problema; \\
\hline \multirow[t]{3}{*}{ Coleta de Material/Informações } & Levantamento bibliográfico preliminar; \\
\hline & Busca das fontes; \\
\hline & Leitura do material; \\
\hline \multirow{3}{*}{$\begin{array}{l}\text { Seleção e organização do material } \\
\text { coletado }\end{array}$} & Fichamento; \\
\hline & Organização lógica do assunto; \\
\hline & Redação do texto \\
\hline
\end{tabular}

Fonte: Elaboração própria a partir de Kauark, Manhães e Medeiros (2010) e Gil (2002) 
Elegemos, para este estudo, as três grandes etapas de Kauark, Manhães e Medeiros (2010) contendo cada uma três passos de Gil (2002). Lembrando que, para tal investigação, buscamos material bibliográfico em plataformas online. Entretanto, salientamos que, em média, quatro de cada cinco trabalhos inicialmente selecionados pelos títulos foram descartados ao analisarmos o resumo, por não mostrarem aderência ao tema da presente investigação. Ainda houve outros descartes após a leitura minuciosa dos textos para que permanecessem apenas materiais pertinentes.

\section{Metodologias ativas de ensino}

A ideia de metodologia ativa já vem sendo comentada há tempos, porém, frequentemente, conforme Barbosa e Moura (2013, p. 54) "os professores conhecem meios de ensinar e aprender que podem ser considerados como um tipo de metodologia ativa, ainda que não sejam rotuladas ou conhecidas por essa expressão". Conforme os mesmos autores, a aprendizagem ativa se dá quando o estudante lê, escreve, questiona, discute ou ocupa-se em resolver problemas ou projetos, desenvolvendo tarefas mentais de alto nível com análise, síntese e avaliação. Ou seja, ela

[...] ocorre quando o aluno interage com o assunto em estudo - ouvindo, falando, perguntando, discutindo, fazendo e ensinando - sendo estimulado a construir o conhecimento ao invés de recebê-lo de forma passiva do professor. Em um ambiente de aprendizagem ativa, o professor atua como orientador, supervisor, facilitador do processo de aprendizagem, e não apenas como fonte única de informação e conhecimento. (BARBOSA; MOURA, 2013, p. 55).

Complementando, Paiva (2016, p. 15) diz que: “Aprendizagem ativa é um conjunto de práticas pedagógicas centradas no estudante de forma que ele aprenda os conhecimentos propostos por meio da interação entre ele e os outros colegas, estimulando o pensamento crítico". Conforme o autor, este método visa uma aprendizagem colaborativa, onde todos os envolvidos são responsáveis pelo sucesso do grupo. Nesta perspectiva, Gastardelli (2016, p. 27) descreve as metodologias ativas como possibilitadoras da "formação de forma dinâmica, integrada e colaborativa, ou seja, o educando passa a representar papel importante no processo de ensino e aprendizagem". Assim, entendemos que tais tendências vêm sendo utilizadas para sanar déficits da educação atual. 
A aula ministrada por meio apenas de exposição de informações já está ultrapassada e os estudantes não devem mais ser tratados como agentes passivos. Esta é a opinião de Paiva (2016) ao declarar que a aula expositiva está obsoleta, pois o estudante não pode ser um repetidor de informações. O educador deve fomentar a criatividade, curiosidade e senso crítico, para que os alunos passem a pensar e refletir sobre os assuntos, formando suas próprias opiniões. Na metodologia ativa, o professor deixa de ter a função de emitir informações e torna-se facilitador do processo de obtenção de conhecimento, e o estudante passa a um contexto dinâmico, com ambiente ativo e construtivo (FARIAS; MARTIN; CRISTO, 2015).

Metodologias tradicionais gradualmente estão sendo substituídas por métodos modernos que possibilitam o desenvolvimento de competências de tomada de decisão, resolução de problemas, entre outras. Assim, conforme Gastardelli (2016), essas metodologias são eficazes para tal processo, pois propiciam aulas com aprendizagem mais significativa. Neste sentido, vemos diversas vantagens para a aprendizagem de qualidade, facilitando a assimilação pelos estudantes e formando pessoas mais aptas para resolver problemas, com maior criatividade. Segundo Barbosa e Moura (2013, p. 56) “[...] com métodos ativos, os estudantes assimilam maior volume de conteúdo, retêm a informação por mais tempo e aproveitam as aulas com mais satisfação e prazer", possibilitando uma aprendizagem dinâmica de maneira que o estudante compreenda de forma ampla qualquer assunto.

São inúmeras as estratégias existentes para métodos ativos de ensino, mas para que sejam consideradas boas, Farias, Martin e Cristo (2015, p.146) trazem os seguintes elementos como principais para manter a qualidade:

Construtivista: se basear em aprendizagem significativa; Colaborativo: favorecer a construção do conhecimento em grupo; Interdisciplinar: proporcionar atividades integradas a outras disciplinas; Contextualizado: permitir que o educando entenda a aplicação deste conhecimento na realidade; Reflexivo: fortalecer os princípios da ética e de valores morais; Crítico: estimular o educando a buscar aprofundamento de modo a entender as limitações das informações que chegam até ele; Investigativo: despertar a curiosidade e a autonomia, possibilitando ao educando a oportunidade de aprender a aprender; Humanista: ser preocupado e integrado ao contexto social; Motivador: trabalhar e valorizar a emoção; Desafiador: estimular o estudante a buscar soluções. (FARIAS; MARTIN; CRISTO, 2015, p. 146).

A fim de compreender melhor as diferentes estratégias de ensino veremos, a seguir, algumas destas que são voltadas para as metodologias ativas de ensino. Feito isso, suscitamos 
o debate sobre a utilização de artefatos Google For Education em estratégias de ensino para uma metodologia ativa.

\section{Estratégias de ensino}

Neste tópico discutimos sobre cinco diferentes estratégias de ensino, a saber: Aprendizagem baseada em problemas; Aprendizagem baseada em projetos; Aprendizagem pelos colegas; Aprendizagem baseada em equipes; e Sala de aula invertida.

\section{Aprendizagem baseada em problemas}

Esta estratégia de ensino é realizada através da descrição de uma situação problema onde os estudantes deverão buscar alternativas de solução. O professor, neste caso, é responsável por orientar, instruir e auxiliar seus educandos no processo de desenvolvimento de novas ideias, quando a interação entre professor-estudante é muito mais intensa (BARBOSA; MOURA, 2013). Sendo assim, esta metodologia foca no “[...] aprendizado por meio do pensamento crítico e reflexivo, o que leva à aplicação de conhecimento da solução de problemas concretos" (GASTARDELLI, 2016, p. 43).

Conforme Barbosa e Moura (2013), a aprendizagem baseada em problemas é a contextualização de um dilema em um aprendizado autodirigido, o qual é centrado no estudante, deixando de ser um receptor passivo da informação e tornando-se agente ativo. Também “[...] conhecida como PBL (Problem Based Learning), esta metodologia surgiu na década de 1960, inicialmente na psicologia comportamental" (FARIAS; MARTIN; CRISTO, 2015, p. 146).

O processo de ensino através de problemas se dá por etapas, divididas em cinco, conforme Barbosa e Moura (2013). Inicialmente se contextualiza o problema em questão e, após, lista-se os possíveis motivos do problema e as soluções potenciais. Na etapa de análise, entende-se com mais detalhamento o problema, passando para formulação de questões que irão nortear o estudo. Em seguida, figuram os objetivos, nos quais se verifica a pretensão da atividade. Posteriormente, acontece a discussão individual ou em grupo, quando é realizado o registro do processo. A penúltima etapa é a de síntese e avaliação, com o resumo dos processos e resultados, finalizando com a apresentação ao grupo. Podemos ver tal processo abaixo na figura 01 : 
Figura 01: Passo a passo da aprendizagem baseada em problemas

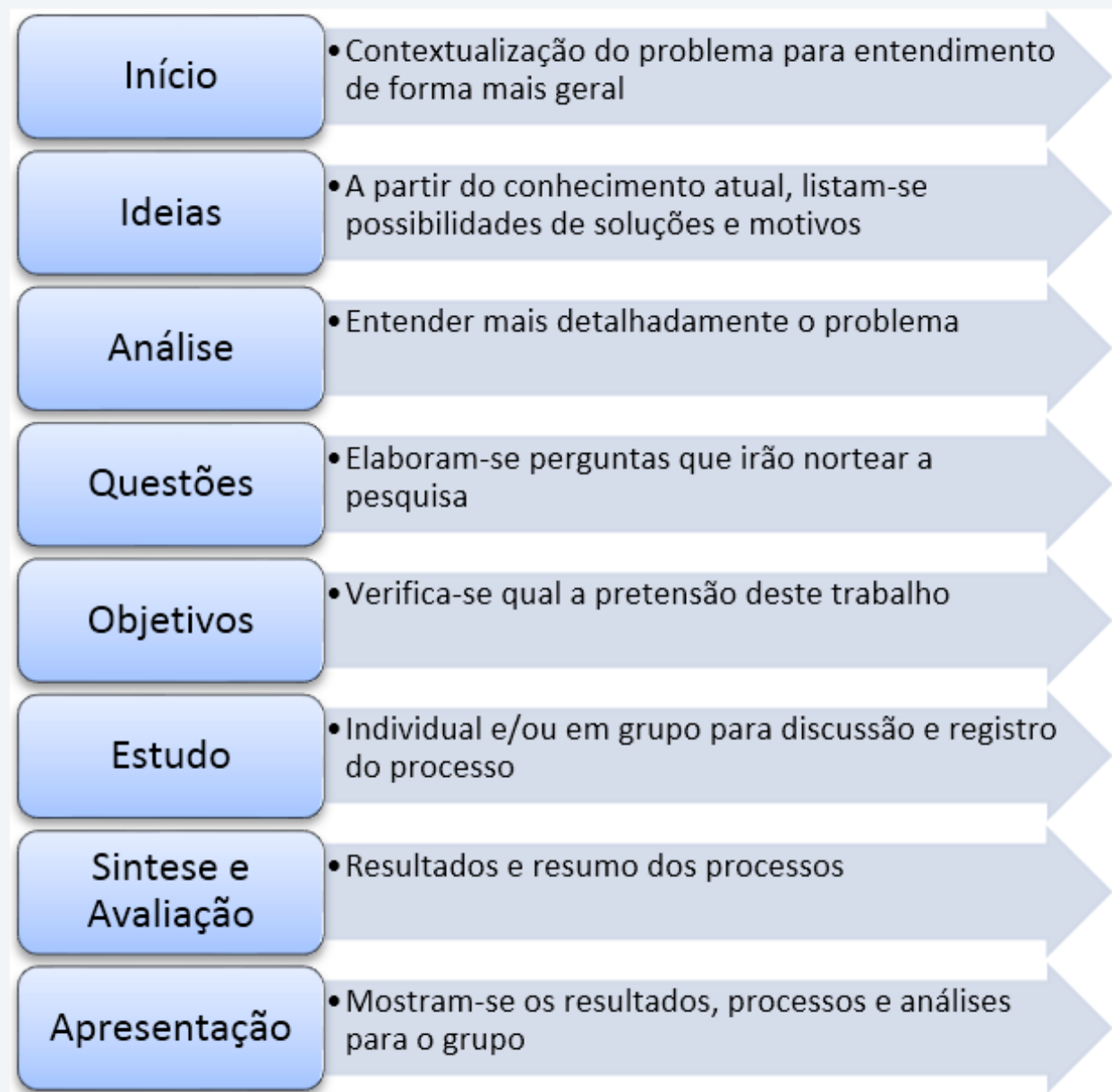

Fonte: Elaborado pelos autores a partir de Barbosa e Moura (2013).

Neste processo nota-se a autonomia do discente durante o processo, no qual ele mesmo precisa, individualmente ou em grupo, pensar de forma criativa e crítica em torno do problema proposto. No tópico a seguir, veremos outra estratégia de ensino-aprendizagem.

\section{Aprendizagem baseada em projetos}

Esta estratégia se dá a partir de algum problema ou necessidade existente, que a partir do qual são traçados objetivos para a elaboração do projeto. Barbosa e Moura (2013) dizem que a aprendizagem baseada em projetos surge da ideia de uma pessoa ou de um grupo, possui objetivos bem definidos e pode ser uma pesquisa, uma invenção, ou algo a desenvolver. Complementando, Gastardelli (2016, p. 43) conceitua como estratégia de ensinoaprendizagem que busca "[...] criar um projeto com determinado tema e voltado para determinado público, para que seja empregado o conteúdo aprendido estudado e explorado pelo aluno na criação de um projeto inovador". 
A aprendizagem baseada em projetos iniciou-se no final do século XIX, com alicerce em ideias de John Dewey, em 1897 (BARBOSA; MOURA, 2013). Desde então houve muitas publicações e experiências escolares visando verificar as potencialidades desta estratégia, e entre os tipos existentes, segundo Barbosa e Moura (2013) é possível fazer uma divisão em três categorias:

Projeto construtivo: tem em vista construir algo novo, introduzindo alguma inovação, propor uma solução nova para um problema ou situação. Possui a dimensão da inventividade, seja na função, na forma ou no processo; Projeto investigativo: destina-se ao desenvolvimento de pesquisa sobre uma questão ou situação, mediante o emprego do método científico; Projeto didático (ou explicativo): procura responder questões do tipo: "Como funciona? Para que serve? Como foi construído?" Busca explicar, ilustrar, revelar os princípios científicos de funcionamento de objetos, mecanismos, sistemas etc. (BARBOSA; MOURA, 2013, p. 63, grifos nossos).

Esta estratégia, assim como a anteriormente citada, possui foco na autonomia do educando, porém, as atividades baseiam-se em torno de um projeto que deve ser executado. Segundo Farias, Martin e Cristo (2015, p. 148): "Esta estratégia atinge níveis taxonômicos elevados, desenvolvendo a capacidade criativa dos estudantes". Verificamos, conforme descreve Paula (2017), cinco etapas para o bom desenvolvimento da aprendizagem a partir de projetos. Esta sequência que organiza o processo, consiste inicialmente em uma pesquisa, passa por definições e planejamento, até chegar à finalização do projeto, com sua execução e avaliação, conforme visualizamos na figura 02 .

Figura 02: Passo a passo da aprendizagem baseada em projetos

\begin{tabular}{|l|l|}
\hline $2^{\circ}$ & - Levantamento do tema através de uma pesquisa; \\
\hline $3^{\circ}$ & - Defininir o cronograma, mantendo relatórios periódicos; \\
\hline $4^{\circ}$ & - Realizar o projeto conforme o cronograma; \\
\hline $5^{\circ}$ & - Avaliar e contextualizar o trabalho, objetivando resultados e aplicação. \\
\hline
\end{tabular}

Fonte: Elaborado pelos autores a partir Paula (2017).

Conforme Farias, Martin e Cristo (2015, p. 148), os estudantes passam por cinco etapas neste processo: “[...] observação da realidade; postos-chave; teorização; hipótese de solução; e aplicação à realidade”. Os mesmos autores entendem que esta estratégia se trata de uma oportunidade de aprendizado em grupo que desenvolve nos estudantes a capacidade de 
enfrentar e resolver problemas imprevisíveis. Neste seguimento, veremos uma estratégia semelhante a esta, que possui maior foco na aprendizagem em grupos.

\section{Aprendizagem pelos colegas}

A aprendizagem baseada em equipes tem em vista o estudo em grupos, de forma colaborativa. Esta estratégia busca a discussão e troca de informações entre estudantes, quando através do diálogo todos possam entender o assunto em questão. Percebe-se que ao existirem discentes que entenderam e outros que ainda não, o diálogo entre estes propagará a compreensão do assunto com maior facilidade.

Também chamado de Peer Instruction, este método “[...] surgiu em 1990 quando o professor Eric Mazur da Universidade de Havard se deparou com uma série de artigos de Halloun e Hestenes sobre o mau aproveitamento da aprendizagem de alunos de graduação nas matérias de física" (PAIVA, 2016, p. 27). A partir daí Eric Mazur passou a perceber que era importante a aprendizagem por colegas para que as questões consideradas fáceis do cotidiano fossem compreendidas pelos estudantes através de discussões entre seus pares, pois seus alunos estavam memorizando o conteúdo, mas não o compreendiam por não terem este debate.

O professor lança um assunto e deixa que os estudantes entre si discutam sobre o mesmo e desta forma desenvolvem seus conhecimentos. Compreendemos a partir de Paiva (2016, p. 26) que: “A aprendizagem pelos colegas (em inglês, Peer Instruction) é uma técnica que tem como objetivo envolver os alunos promovendo a discussão entre eles de tópicos propostos pelo professor". A figura 03 apresenta o desenvolvimento da aprendizagem pelos colegas.

Figura 03: Desenvolvimento da aprendizagem pelos colegas

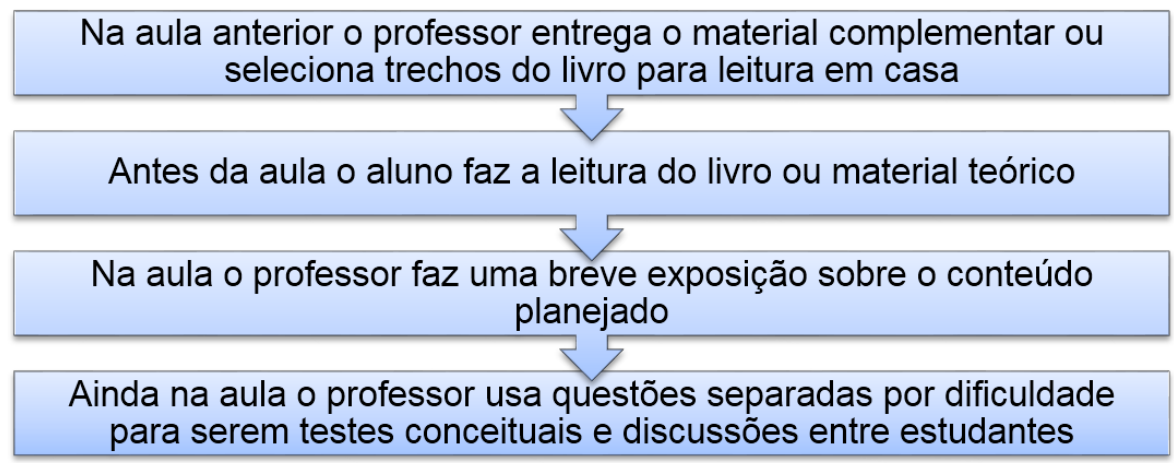

Fonte: Elaborado pelos autores a partir de Paiva (2016). 
Esta estratégia tem foco na interação entre estudantes, quando longas aulas detalhadas são substituídas por apresentações curtas de assuntos que os estudantes irão discutir. Após, realizarão um teste conceitual (PAIVA, 2016). Este processo é realizado em seis etapas conforme Paiva (2016, p. 33):

\begin{abstract}
1.Estudantes completam a leitura ou os outros trabalhos preparatórios; 2.Estudantes fazem o teste de leitura; 3.Um membro do corpo docente comenta as tarefas de leitura, e considera mudanças na ênfase da aula; 4.Um membro da faculdade seleciona citações das tarefas de leitura para se referir durante a aula; 5. Durante a aula, um membro do corpo docente usa citações de trabalhos dos alunos para liderar a discussão do material;6. Durante a aula, os alunos se envolvem na discussão do material com o membro do corpo docente e um com o outro.
\end{abstract}

Esse processo tem como objetivo central fazer com que os alunos se empenhem no processo de aprendizagem. Paiva (2016, p. 30) diz que uma boa vantagem desta metodologia é que o feedback é imediato, comenta que: "O professor sabe a cada resposta mostrada pelos alunos, qual a porcentagem de alunos que provavelmente entendeu o conceito, pois acertaram uma questão proposta". Na sequência, veremos outra estratégia que se assemelha muito a esta, porém tem como elemento central, a equipe.

\title{
Aprendizagem baseada em equipes
}

Esta estratégia surgiu no final dos anos 70 pelo professor de gestão e negócios Larry Michaelsen na Universidade de Oklahoma (EUA). Seu objetivo consiste em melhorar a aprendizagem e desenvolver habilidades de trabalho colaborativo (MICHAELSEN; KNIGHT; FINK, 2004). Farias, Martin e Cristo (2015) explicam a aprendizagem baseada em equipes como TBL (Team Based Learning), na qual se trabalha com uma aprendizagem dinâmica com ambiente motivador e cooperativo, valorizando a produção coletiva. Estes autores descrevem o meio detentor de um ambiente mais interessante para o aprendizado. Complementando, Bandeira, Silva e Vilela (2017, p. 377) esclarecem: “Os estudantes enfatizam que as aulas ficaram mais dinâmicas, participativas, produtivas e fazem com que eles estudem mais e interajam no grupo para resolver as atividades propostas".

No mesmo sentido, Farias, Martin e Cristo (2015) descrevem esta estratégia de ensinoaprendizagem em três fases, sendo elas: a) Preparação, análise do conteúdo e estudo individual; b) Compromisso compartilhado, testes individuais, em grupos e explicações do especialista; e c) Aplicação dos conhecimentos do curso, atividade orientada para 
aprofundamento do conteúdo. Podemos verificar no quadro 02 o processo do ensino baseado em equipes.

Quadro 02: Fases de execução da aprendizagem baseada em equipes

\begin{tabular}{l|l|l}
\multicolumn{1}{c|}{ Preparação } & Compromisso compartilhado & \multicolumn{1}{|c}{$\begin{array}{c}\text { Aplicação dos conceitos } \\
\text { do curso }\end{array}$} \\
\hline $\begin{array}{l}\text { Estudo individual. Leitura } \\
\text { dos textos sobre temas } \\
\text { recomendados. Análise do } \\
\text { material de estudo. }\end{array}$ & $\begin{array}{l}\text { Teste individual. Teste em } \\
\text { grupo. Explicações do } \\
\text { especialista, presencialmente } \\
\text { ou a distância. }\end{array}$ & $\begin{array}{l}\text { Aplicação de uma } \\
\text { atividade orientada. } \\
\text { Aprofundamento do } \\
\text { assunto. }\end{array}$
\end{tabular}

Farias, Martin e Cristo (2015, p. 147)

Fonte:

De acordo com Bandeira, Silva e Vilela (2017), esta estratégia possibilita a prática de pensamento crítico, resolução de problemas e interação entre professores e estudantes. Estes autores ainda complementam dizendo que a partir de tais práticas, o trabalho em equipe é estimulado, assim como a capacidade de negociação. Este processo de ensino incentiva o estudante a realizar uma avaliação de si próprio, refletindo sobre seu desempenho. Portanto, percebe-se que "[...] o aluno que se auto-avalia revela um grande envolvimento pessoal no processo de avaliação, gerindo e refletindo sobre o seu desempenho, tornando-se assim regulador da sua própria aprendizagem" (BANDEIRA; SILVA; VILELA, 2017, p. 378).

Após um bom entendimento sobre as estratégias de ensino-aprendizagem listadas acima, veremos no tópico 3.5 o conceito da sala de aula invertida.

\section{Sala de aula invertida}

A quinta estratégia apresentada, a sala de aula invertida, objetiva uma aprendizagem baseada na autonomia do estudante, o qual deve buscar sozinho pelas informações. Também conhecida conforme Suhr (2016), como Flipped Classroom, foi divulgada por Bergmann e Sams (2012) após a experimentarem a fim de atender a alunos atletas, que se ausentavam das aulas devido aos seus compromissos em campeonatos. Porém, esta estratégia existe desde "[...] a década de 1990, com o crescimento das possibilidades de uso e acesso às Tecnologias de Informação e Comunicação (TIC)" (Suhr, 2016, p. 6).

$\mathrm{Na}$ sala de aula invertida, os papeis são trocados, o educando passa a estar no centro do processo de aprendizagem e tomar atitudes sobre as discussões. De acordo com Santos, Oliveira e Alves (2016, p. 2), “[...] os estudantes ao invés de serem meros ouvintes, passam a ser agentes ativos do processo, e o professor com a função de apresentar e discutir as análises sobre o tema". Os autores ainda esclarecem que

Nesse novo modelo o aluno passa a ter autonomia e pode estudar e acessar a informação onde e quando quiser, por meio dos materiais que o professor disponibiliza em suportes digitais ou outros formatos. Assim, espera-se que os alunos cheguem em sala de aula, já com embasamento prévio do que será trabalhado em sala. Nesse sentido, o professor deixa de ser o único detentor 
do saber e passa a ser um mediador do debate e do andamento do processo educativo. (SANTOS; OLIVEIRA; ALVES, 2016, p. 03).

A sala de aula invertida ou Flipped Classroom abordada por Farias, Martin e Cristo (2015) é um modelo que, entre outras possibilidades, traz o uso das Tecnologias da Informação e Comunicação (TIC). Assim, proporciona alternativas inimagináveis, pois o aluno pode estudar da forma como achar melhor, utilizando a internet. Dessa maneira, professor e estudante alcançam diversas informações para auxiliar no aprendizado. Sua proposta é fazer com que os estudantes levem a parte conceitual para ser estudada em casa e o tragam o momento de autonomia para dentro da sala de aula. Segundo Bergmann e Sams (2016, p. 11): “[...] o que tradicionalmente é feito em sala de aula, agora é executado em casa, e o que tradicionalmente é feito como trabalho de casa, agora é realizado em sala de aula". Na Figura 04 podemos visualizar este modelo de ensino pela divisão de tarefas para antes, durante e depois da aula, quando verificamos que a estratégia inverte-se concordando com Bergmann e Sams (2016).

Figura 04: Sala de aula invertida
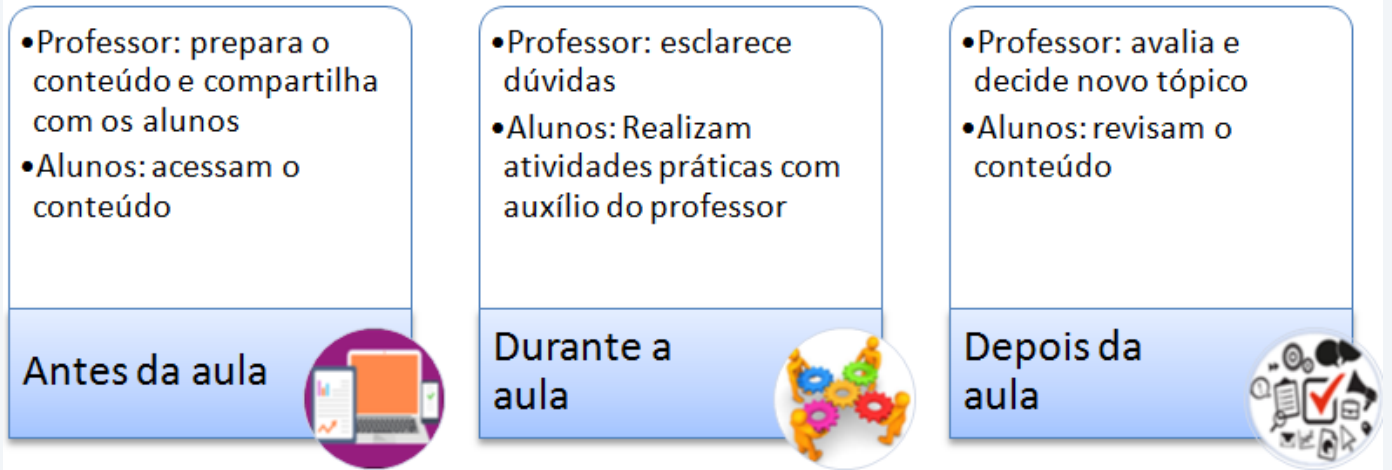

Fonte: Elaborado pelos autores a partir do referencial.

Nesta estratégia, o professor deixa de ser mero transmissor de informações, conceitos, e passa a orientar e guiar os estudantes no seu processo de aprendizagem. Por sua vez, os estudantes passam a ser mais importantes no desenvolvimento das aulas, pois cada um trabalha de forma diferente na sua própria aprendizagem. Complementando, Bergmann e Sams (2016) descrevem o professor como tutor ou orientador dos estudantes, que pode personalizar o ensino conforme a sua necessidade para melhorar a qualidade da aprendizagem. 


\section{Google For Education como artefato para as diferentes estratégias de ensino- aprendizagem}

Neste tópico buscamos compreender a utilização dos artefatos da Google For Education nas cinco estratégias de ensino-aprendizagem citadas nesta pesquisa, que visam metodologias ativas. Mas, de que forma eles podem contribuir para as metodologias ativas? Veremos a seguir as possibilidades desta plataforma de aplicativos para nos auxiliar em todas as estratégias de ensino-aprendizagem como as anteriormente descritas (Aprendizagem baseada em problemas; Aprendizagem baseada em projetos; Aprendizagem pelos colegas; Aprendizagem Baseada em Equipes; e Sala de aula invertida).

A Google For Education foi lançada em agosto de 2014 com o intuito de auxiliar professores e alunos no processo educacional. Disponibiliza inúmeros aplicativos que facilitam o processo, otimizando o tempo de estudantes e educadores. Assim, entendemos que a Google For Education pode ser utilizada em todas as cinco estratégias descritas nesta pesquisa, pois por meio dela é possível desenvolver uma aprendizagem ativa, seja baseada em problemas, projetos, discussão entre colegas, por equipe ou em sala de aula invertida, conforme figura 05.

Figura 05: Google For Education

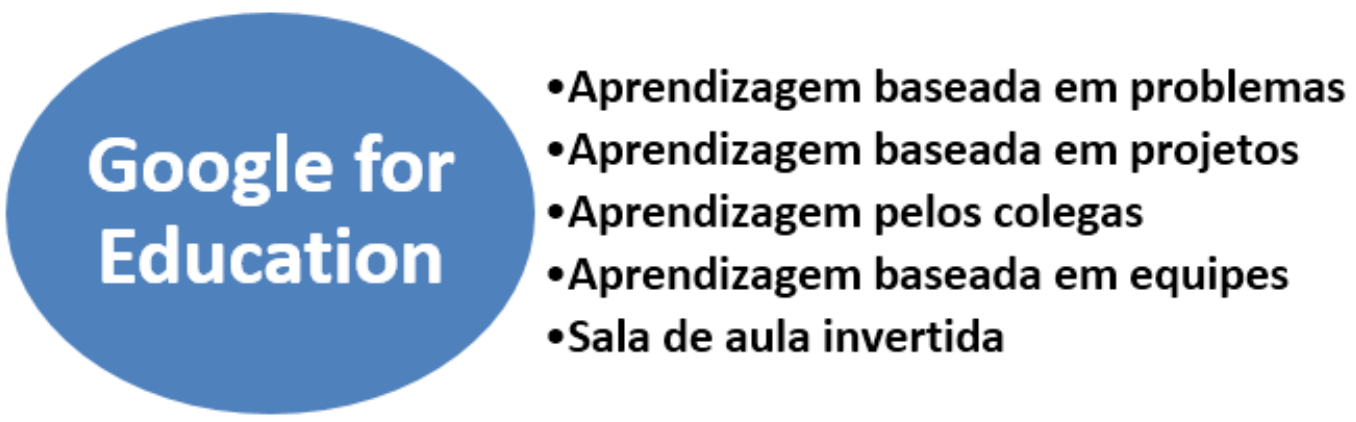

Fonte: Elaborado pelos autores a partir de dados da pesquisa, 2018.

Percebemos que as estratégias listadas podem ser apoiadas por meio dos artefatos de pesquisa da Google For Education, facilitando o acesso a informações. Estes artefatos conectam estudantes e docentes para que possam trocar ideias, conteúdos e experiências, o que facilita o acesso ao debate sobre problemas, dúvidas, conceitos, entre outros.

É possível, no Google Sala de Aula, criar grupos e equipes que poderão compartilhar documentos, conversas, agendar tarefas, trocar opiniões entre outras funcionalidades, facilitando a aprendizagem coletiva. Os aplicativos Google For Education interligam docentes 
e discentes em um ambiente online, gratuito e de fácil acesso. Estes meios de comunicação permitem a utilização da metodologia de aprendizagem pelos colegas, pois tornam possível a comunicação entre eles de qualquer lugar com acesso à internet, facilitando debates e discussões para melhor compreensão do aluno.

A sala de aula invertida pode ser também combinada com outras citadas anteriormente, sendo amparada pela Google For Education, pois está baseada na ideia de o estudante procurar informações e se esforçar por sua aprendizagem. Os aplicativos, por sua vez, colaboram para a formação de alunos autônomos.

Com os avanços tecnológicos, surgem novos recursos para uma educação por meio de metodologias ativas. Conforme Nóbrega, Da Costa e Araújo (2016), a era da informação aponta questões sobre a educação contemporânea, quando se idealizam sistemas educacionais inovadores que aperfeiçoem seus serviços e aumentem seus resultados. Assim, segundo Pérez (2011, p. 3-4): "La educación formal, es un elemento clave en el desarrollo de un país y aunado al uso de las tecnologías de información y comunicación como medio para favorecer el acceso y uso del información por parte del estudiantado".

Verificamos a existência de diversos novos artefatos que podem ampliar as possibilidades de estratégias de ensino-aprendizagem. Em concordância, Pérez (2011, p. 4) afirma que a tecnologia proporciona um espaço inovador de aprendizagem colaborativa, pois

El uso de la amplia gama de recursos 2.0 en el entorno educativo puede hacer de las estrategias tradicionales de enseñanza, un nuevo espacio para la construcción colaborativa de aprendizaje, que propicie un mayor involucramiento estudiantil y un nuevo entorno de interacción en el que, lo presencial se conjuga con lo digital en con un solo propósito que es formar en el desarrollo de competencias disciplinares y en uso de TIC.

A Google For Education é uma plataforma de aplicativos destinados à educação, ou seja, “[...] fornece ferramentas fáceis de usar para envolver os alunos a qualquer hora, em qualquer lugar e em qualquer dispositivo" ". Esta plataforma foi lançada em agosto de 2014 pela Google e desde então vem passando por constantes atualizações para melhorar sua performance.

Assim como outras tecnologias, a Google For Education precisa ser aplicada da forma correta para que tenha maior aproveitamento. É preciso capacitar e preparar a equipe docente aos avanços no ensino, para que os educadores estejam aptos a utilizar tais artefatos tecnológicos, como a Google For Education, da forma mais correta e benéfica. Percebemos,

\footnotetext{
${ }^{5}$ Disponível em: https://edu.google.com/intl/pt-BR. Acessado em: 15 fev. 2018.
} 
conforme Nóbrega, Da Costa e Araújo (2016, p. 3) que: “A implantação das novas tecnologias nos processos educacionais leva para o centro não só os instrumentos técnicos, como é o caso do Google for Education, mas promove uma discussão também sobre seus modos de utilização".

Um dos principais artefatos da Google para a educação é a "Google Sala de Aula", (Google Classroom) que possibilita a conexão entre docentes e discentes de qualquer lugar que possua rede de internet. Facilita a comunicação e troca de informações por mensagens, envio de materiais, entrega e correção de trabalhos, postagens de notas, comunicados, entre outros.

Conforme o site7 da Google, a Classroom tem como objetivos: Configuração fácil para criar e gerenciar turmas, convidar alunos e professores auxiliares, compartilhar informações, tarefas e avisos; Poupar tempo e papel; Maior organização, pois os alunos veem suas tarefas e os materiais didáticos são guardados em pastas do Google Drive; Comunicação e feedback aprimorados; Funciona com aplicativos de uso comum, como GoogleDocs, Gmail, Google Drive, Formulários Google etc.; É acessível, seguro e gratuito, sem exibir anúncios e nunca publica dados dos alunos.

Através da Google For Education notamos que inúmeras metodologias ativas de ensino podem ser manipuladas. Os aplicativos desta plataforma visam facilitar e ampliar o acesso à informação, auxiliando na melhoria do processo de ensino-aprendizagem.

São estratégias que possibilitam o ensino-aprendizagem por meio da metodologia ativa, destacando-se as Tecnologias da Informação e Comunicação (TIC). Tais evoluções na metodologia de ensino são extremamente importantes, assim como Barbosa e Moura (2013, p. 53) complementam dizendo que "Não há dúvida quanto à sua necessidade no contexto educacional, por se tratar de um conhecimento imprescindível em qualquer área da atividade humana".

A aprendizagem ativa é aquela que engloba diversas atividades em uma mesma metodologia em busca da melhor compreensão pelo estudante do que está sendo ensinado. $\mathrm{O}$ educando aprende mais quando se envolve na situação que lhe é passada, então, como descrevem Barbosa e Moura (2013, p. 55), a aprendizagem ativa é aquela que favorece ao estudante atividades que envolvam “[...] ouvir, ver, perguntar, discutir, fazer e ensinar".

Também é uma destas estratégias, o trabalho em grupos, discussões ou decisões coletivas que fazem com que o estudante comece a desenvolver a capacidade de trabalhar em

\footnotetext{
${ }^{6}$ Disponível em: https://goo.gl/Gt3TM3

${ }^{7}$ Disponível em: https://goo.gl/vPgjox
} 
equipe. Profissionais que se formam já com habilidades e competências para o trabalho em equipe são muito mais valorizados. Essas vantagens destacam os futuros profissionais no mercado de trabalho. Assim, é necessário

[...] desenvolver a competência de saber trabalhar em equipe, ocasião na qual aluno só tem a ganhar, pois quando o aluno aprende a trabalhar de forma cooperativa, discutindo e expondo suas opiniões, ele se prepara melhor para o mercado de trabalho futuro, que procura pessoas que saibam trabalhar em equipes multiprofissionais (PAIVA, 2016, p. 17).

Conforme a pesquisa realizada por Mendes et. al. (2017), foram analisadas as percepções dos estudantes de um curso de Administração sobre o processo de implantação de estratégias de metodologias ativas, tendo como amostra 30 alunos do curso. A partir desta investigação, os autores verificaram que 96,7\% dos estudantes responderam que aprovam totalmente ou parcialmente a estratégia metodológica ativa de ensino. Assim, averiguaram que a maioria $(83,4 \%)$ prefere a educação de uma forma conjunta entre os métodos tradicionais e os ativos. O estudo aponta para um número significativo de aderência à implantação das estratégias de metodologias ativas de ensino-aprendizagem.

As estratégias de metodologias ativas possibilitam um desenvolvimento mais amplo dos estudantes, potencializando muitas habilidades, entre elas, Mendes et. al. (2017) elegem: empoderamento; raciocínio crítico; abordagem biopsicossocial; contato com o serviço; contato com a comunidade; trabalho em equipe; responsabilidade; e autonomia. Conforme dados da pesquisa deste mesmo autor, os estudantes indicam como atitudes mais importantes desenvolvidas por esta estratégia: “[...] trabalho em equipe (83\%), responsabilidade (77\%) e autonomia (67\%)" (MENDES et. al, 2017, p. 189 e 190).

Com a estratégia de metodologias ativas, a participação nas aulas é maior e mais significativa, com melhores resultados. O envolvimento entre docente e discente, sendo o segundo focado no seu próprio processo de aprendizagem torna o aprendizado mais intenso e atraente. $\mathrm{Na}$ investigação mencionada,

Os discentes afirmaram ainda que, com a metodologia de ensino ativa, participaram mais das aulas, leram mais as bibliografias recomendadas e desenvolveram habilidades, atitudes essenciais para a vida profissional. Além disso, segundo os informantes, o ensino gerado a partir da metodologia ativa seria mais significativo (MENDES et. al, 2017, p. 189 e 191).

Entre tantas estratégias, os artefatos Google For Education se mostraram uma novidade favorável para a educação, disponibilizando aplicativos gratuitamente, que facilitam 
e agilizam os processos envolvidos na educação, além de possibilitarem ambientes de troca de informação e conteúdos. Esta prática acaba por romper com o ensino tradicional e dá foco ao ensino através da estratégia da metodologia ativa. Portanto, conforme Pérez (2011, p.13):

El uso de los recursos de Google para desarrollar estrategias didácticas con el estudiantado es válido, siempre que se tenga dominio de la herramienta por parte del docente, claridad en los contenidos y una intención educativa que motive la participación e involucramiento de todos los actores en el aprendizaje.

Algumas das principais contribuições da plataforma Google para a educação são: total disponibilidade de acesso; armazenamento ilimitado; permite maior interação; maior feedback; e total segurança e privacidade. Isso porque a Google For Education possui gratuitamente diversos artefatos educacionais com o objetivo de aprimorar o ensino envolvendo os estudantes no processo de forma mais intensa.

\section{Considerações finais}

Existem muitas estratégias de ensino que possibilitam metodologias ativas, e vem surgindo cada vez mais recursos. A aula expositiva tem perdido espaço. Portanto, se faz importante a preparação de docentes para a nova era da educação em que estamos. Esta pesquisa teve como objetivo suscitar o debate em busca da utilização de artefatos Google For Education em estratégias de ensino para uma metodologia ativa. Para fundamentar nossa discussão descremos cinco estratégias de ensino que são compreendidas pelas metodologias ativas: aprendizagem baseada em problemas; aprendizagem baseada em projetos; aprendizagem pelos colegas; aprendizagem baseada em equipes e sala de aula invertida.

A aprendizagem baseada em problemas descreve um cenário no qual os estudantes se deparam com um dilema e a partir de então passam a discutir para entendê-lo e encontrar formas de resolvê-lo e, por fim, os resultados são apresentados ao grande grupo. Já a aprendizagem por projetos se assemelha por possuir um tema inicial, porém, este é definido em conjunto, assim como o cronograma do processo. Após o projeto é posto em prática conforme descrito para, finalmente, avaliar e contextualizar o trabalho realizado.

$\mathrm{Na}$ aprendizagem pelos colegas, o professor disponibiliza com antecedência o material para ser lido em casa pelos estudantes e, durante a aula, tira dúvidas e provoca discussões sobre o tema para que os estudantes aprendam entre si. Semelhante a esta é a aprendizagem baseada em equipes, que também contempla a leitura dos materiais indicados, seguida da 
explicação de um especialista que, posteriormente, aplica uma atividade orientada em equipe. E na sala de aula invertida também se disponibilizam os materiais com antecedência, para que os estudantes façam a leitura e no encontro presencial tragam suas dúvidas. O professor esclarecerá incertezas e aplicará atividades práticas para que o educando se familiarize com o assunto.

Dentre tecnologias disponíveis, encontramos a Google For Education como principal artefato tecnológico a ser utilizado em estratégias que visem as metodologias ativas de ensino. A Google disponibiliza variados aplicativos que poderão fomentar a autonomia ao estudante, além do desenvolvimento da criatividade, criticidade e empreendedorismo. Esta tecnologia é bastante completa, tanto que é possível utilizá-la em todas as cinco estratégias descritas na pesquisa, podendo se expandir esta área em próximas investigações.

Nota-se a importância da aplicação das estratégias que se compõem de metodologias ativas de ensino por meio de artefatos tecnológicos que envolvam cada vez mais o estudante no seu processo de aprendizagem. A Google For Education traz aplicativos que auxiliam a educação e compreendem a realidade da nova geração de educandos, o que possivelmente poderá atraí-los e mantê-los interessados mais facilmente.

Entretanto, nenhum desses recursos opera sozinho. Ou seja, é necessário que os docentes estejam preparados para o seu uso didático e que recebam apoio neste sentido da equipe gestora. Desta forma, esta pesquisa poderá suscitar estudos futuros na área, no sentido de trazer a percepção docente sobre o uso destas estratégias.

\section{REFERÊNCIAS}

BANDEIRA, Denise Maria Almeida; SILVA, Maria Alexsandra; VILELA, Rosana Quintella B. Aprendizagem baseada em equipe. Revista Portal: Saúde e Sociedade. v. 2, n. 1, p. 371 379, 2017. Disponível em: https://goo.gl/wX7N6V. Acessado em: 10 fe. 2018.

BARBOSA, Eduardo Fernandes; MOURA, Dácio Guimarães de (2013). Metodologias ativas de aprendizagem na Educação profissional e Tecnológica. Revista Senac. B. Tec. Senac, Rio de Janeiro, v. 39, n. 2, p. 48-67, maio/ago. Disponível em: https://goo.gl/mMehY2. Acessado em: 15 jan. 2018.

BERGMANN, Jonathan; SAMS, Aaron. Sala de aula invertida: Uma metodologia ativa de aprendizagem. Trad. Afonso Celso da Cunha Serra. 1. ed. Rio de Janeiro: LTC, 2016.

FARIAS, Pablo Antonio Maia de; MARTIN, Ana Luiza de Aguiar Rocha; CRISTO, Cinthia Sampaio. Aprendizagem Ativa na Educação em Saúde: Percurso Histórico e Aplicações. 
Revista brasileira de Educação Médica, v. 39, n. 1, p. 143-158, 2015. Disponível em: https://goo.gl/fMufYN. Acessado em: 03 fev. 2018.

PAULA, Leonardo Tavares de. Ensino de fisica por projetos - a física do forno solar. Dissertação de Mestrado - Universidade Federal de Juiz de Fora, 2017. Disponível em: https://goo.gl/HUvH8y. Acessado em: 29 jan. 2018.

MENDES, Andréia Almeida, et al. A percepção dos estudantes do curso de administração a respeito do processo de implantação de metodologias ativas de ensino-aprendizagem - o desenvolvimento da aprendizagem significativa. Revista Pensar Acadêmico, Manhuaçu, v. 15, n. 2, p. 182-192, 2017. Disponível em: https://goo.gl/N52pR6. Acessado em: 20 fev. 2018 .

GASTARDELLI, Gustavo. Metodologias ativas: desafios para uma educação distuptiva. Propale*com. Porto Alegre, 2016.

GIL, Antônio Carlos. Como elaborar projetos de pesquisa. São Paulo: Atlas, 2002.

KAUARK, Fabiana da Silva, MANHÃES, Fernanda Castro, MEDEIROS, Carlos Henrique. Metodologia da pesquisa: um guia prático. Itabuna: Via Litterarum, 2010.

MICHAELSEN, Larry K.; KNIGHT, Arletta Bauman; FINK, L. Dee. Team-Based Learning: A transformative use of small groups in college teaching. Sterling, VA: Stylus Publishing, LLC, 2004.

NÓBREGA, Josley Maycon de Sousa; DA COSTA, Antonio Roberto Faustino; ARAÚJO, Patrícia Cristina de Aragão. Google for education na rede pública do estado da Paraíba. In: III Congresso Nacional de Educação, Natal/RN, 2018. Anais [...] Natal: III CONEDU, 2016. Disponível em: http://bit.ly/2F8ZBZu. Acessado em: 10 jan. 2018.

PAIVA, Thiago Yamashita. Aprendizagem Ativa e Colaborativa: uma proposta de uso de metodologias ativas no ensino da matem ática. Dissertação (Mestrado EM Matemática) Universidade de Bras' 1 lia, 2016.

PÉREZ, Esteban González. Recursos de Google para el desarrollo de una unidad didáctica con estudiantes de educación superior. Revista Actualidades Investigativas en Educación, v. 1, n. 1, p. 1-15, 2011. Disponível em: https://goo.gl/ckkn9M. Acessado em: 03jan. 2018.

SANTOS, Leandro Santana; OLIVEIRA, Kaio Eduardo de Jesus; ALVES, André Luiz. Sala de aula invertida e novas tecnologias: uma nova proposta de ensino. $11^{\circ} \mathrm{FOPIE}$ - Fórum permanente internacional de inovação educacional, 2016. Disponível em:

https://goo.gl/xbosde. Acessado em: 05 jan. 2018.

SUHR, Inge Renate Frose. Desafios no uso da sala de aula invertida no ensino superior. Revista Transmutare, Curitiba, v. 1, n. 1, p. 4-21, 2016. Disponível em: https://goo.gl/Qf8H9P. Acessado em: 27 jan. 2018.

VALENTE, José Armando; ALMEIDA, Maria Elizabeth Bianconcini; GERALDINI, Alexandra Flogi Serpa. Metodologias ativas: das concepções às práticas em distintos níveis de 
ensino. Revista Diálogo Educacional, Curitiba, v. 17, n. 52, p. 455-478, 2017. Disponível em: http://bit.ly/2t9QAtH. Acessado em: 11 fev. 2018.

\section{SOBRE OS AUTORES}

\section{Louise de Quadros da Silva}

Mestranda em Educação na Universidade La Salle Canoas/RS. Bolsista Institucional. Integrante do grupo de pesquisa Gestão Educacional nos diferentes contextos. E-mail: louise.quadrosdasilva@gmail.com

(iD https://orcid.org/0000-0002-8632-3374

\section{Paulo Fossatti}

Doutor em Educação. Reitor da Universidade La Salle, Canoas/RS e docente do PPG Educação desta universidade. Líder do grupo de pesquisa Gestão Educacional nos diferentes contextos. E-mail: paulo.fossatti@unilasalle.edu.br

iD http://orcid.org/0000-0002-9767-5674

\section{Hildegard Susana Jung}

Doutora em Educação. Docente do Curso de Pedagogia e colaboradora do PPG Educação da Universidade La Salle Canoas/RS. Integrante do grupo de pesquisa Gestão Educacional nos diferentes contextos. E-mail: hildegard.jung@unilasalle.edu.br

(iD http://orcid.org/0000-0001-5871-3060 